доктор экономических наук, профессор Института экономики РАН

\section{НАЦИОНАЛЬНЫЕ ПРОЕКТЫ В СИСТЕМЕ СТРАТЕГИЧЕСКОГО ПЛАНИРОВАНИЯ В РОССИЙСКОЙ ФЕДЕРАЦИИ}

Doctor of Sciences (Economics), Professor, Institute of Economics, Russian Academy of Sciences
Аннотация:

Национальные проекты, разрабатываемые в соответствии с Указом Президента Российской Федерации № 204 от 7 мая 2018 г., занимают особое место в формирующейся системе стратегического планирования в стране. Несмотря на то что действующее законодательство о стратегическом планировании не содержит прямого указания на национальные проекты как документ, присущий такой системе управления, очевидно, что эти проекты неизбежно займут важное место как в определении ключевых приоритетов хозяйственного и социального развития страны на перспективу, так и в выявлении путей их практического достижения. Актуализируется проблема согласования национальных проектов с действующей системой государственных (целевых) программ, а на региональном уровне - с региональными программами и проектами, а также с уже действующими и только разрабатываемыми стратегиями социально-экономического развития субъектов Российской Федерации. Делается вывод о необходимости использовать национальные проекты для становления практики проектного управления и бюджетирования, а также закрепить функции этих проектов и их региональной «проекции» $в$ законе о стратегическом планировании.

\section{Ключевые слова:}

стратегическое планирование, государственные программы, национальные проекты, субъекты Российской Федерации, региональные проекты, законодательное регулирование.
NATIONAL PROJECTS IN THE STRATEGIC PLANNING SYSTEM IN THE RUSSIAN FEDERATION
Summary:

National projects being developed in accordance with the Decree of the President of the Russian Federation No. 204 dated May 07, 2018 are emphasized in the emerging strategic planning system in the country. Despite the fact that the current legislation on strategic planning makes no explicit reference to national projects as a document inherent in such a management system, it is obvious that these projects will play a pivotal role in both determining the key economic and social development priorities of the country in the future and identifying the ways to put them into practice. The study focuses on the coordination of national projects with the current system of state (target) programs, regional programs and projects as well as existing and emerging social and economic development strategies of the constituent entities of the Russian Federation. The author concludes that it is necessary to use national projects for establishing project management and budgeting practices. The functions of these projects and their regional projections should be enshrined in the law on strategic planning.

2018 год ознаменовался еще одним масштабным обращением системы государственного управления в Российской Федерации к разработке и реализации национальных проектов. Впервые подобные проекты обозначили себя как инструмент среднесрочного и даже долгосрочного целеполагания в управлении хозяйственными и социальными процессами в стране на рубеже 2005-2006 гг. На данном этапе приоритетными направлениями проектов стали такие сферы, как здравоохранение, образование, жилье, сельское хозяйство. Позднее сюда были включены проектные наработки по таким направлениям, как демография и доступное жилье. Уже тогда большое внимание было уделено вопросу согласования национальных проектов с иными инструментами государственного управления, прежде всего программно-целевого характера. Однако на данном этапе целостный механизм эффективного управления национальными проектами так и не сложился. Возникали проблемы межведомственной координации в реализации проектов, согласовании решений, принимаемых на федеральном и региональном уровне, и пр. Не сложилось и целостной нормативно-правовой базы по разработке и реализации национальных проектов [1]. В результате к концу 2000-х гг. первый «транш» национальных проектов целиком интегрировался в более отлаженную систему государственных (целевых) программ федерального уровня.

Новое обращение к использованию инструмента национальных проектов происходит в заметно изменившихся институциональных и экономических условиях. В середине 2000-х гг. законодательства о стратегическом планировании еще не существовало; фактически отсутствовала и долгосрочная концепция социально-экономического развития страны, которую можно было бы использовать как ключевой ориентир социально-экономической политики государства на средне- и 
долгосрочную перспективу. В этом смысле именно национальные проекты, инициированные президентом РФ, виделись как вполне приемлемый инструмент, способный ориентировать эту политику на наиболее значимые приоритеты хозяйственного и социального развития страны. Как отмечали эксперты, «система национальных проектов позволила четко сформулировать приоритеты государственной политики по указанным направлениям деятельности, определить основные цели и направления развития, разработать и приступить к реализации планов мероприятий, способствующих решению поставленных задач, а также повысить эффективность расходования бюджетных средств, направляемых на фринансирование соответствующих направлений» [2]. К тому же середина 2000-х и сейчас видится как череда «тучных лет», когда появившиеся вследствие благоприятных внешнеэкономических фракторов дополнительные бюджетные доходы требовали их оперативного направления на решение насущных задач экономики страны и ее регионов.

В настоящее время общеэкономический и институциональный фон подготовки и реализации национальных проектов выглядит несколько иначе. Вся совокупность внешнеэкономических факторов развития страны, включая ее главный компонент - цены на нефтегазовые ресурсы, складывается значительно менее благоприятно, не говоря уже об ограничениях санкционного характера. Формально это требует в максимальной мере сконцентрировать экономические ресурсы государства, избежать их избыточного рассредоточения по различным каналам финансирования приоритетных задач хозяйственного и социального развития и, главное, в полной мере подчинить эти каналы и соответствующие им финансовые инструменты единому началу. В роли такового должна была выступить Стратегия социально-экономического развития Российской Федерации, основное содержание, а также порядок разработки и реализации которой определены ст. 16 Закона о стратегическом планировании [3]. Однако три года активных дискуссий вокруг многочисленных инициативных проектов и вариантов подобной стратегии, по сути, ни к чему не привели. Установленные законом сроки прошли, а важнейший документ стратегического видения перспектив российской экономики так и не появился.

Это делает возможным три варианта оценки создавшейся в этой сфере ситуации и ее перспектив: подобная стратегия вообще не нужна; объективно сложные экономические условия данного этапа крайне затрудняют реализацию функций стратегического планирования для России; имеющийся научно-экспертный потенциал страны недостаточен для того, чтобы в этих сложных условиях подготовить стратегический документ не декларативного, а рабочего характера. По всей видимости, совокупность этих обстоятельств и привела к необходимости в очередной раз обратиться к такому паллиативу стратегического планирования, как национальные проекты.

Правда, следует признать, что в настоящее время практика подготовки и реализации национальных проектов выходит на качественно новый уровень. Сравнения показывают, что 12 национальных проектов (каждый из них «распадается» на определенное число «федеральных проектов»), сформированных по Указу Президента РФ № 204, характеризуются большей масштабностью. «Новые» национальные проекты также отличаются более конкретным и развернутым целеполаганием, четко сформированной системой управления проектами и контроля за их фрактическим исполнением, а также и бо̀льшим вниманием к вопросам ресурсной обеспеченности данных проектов и эффективности используемых на эти цели средств. Значительное внимание уделено в настоящее время организации федерально-региональных взаимодействий в процессе реализации национальных проектов, в том числе и их финансирования. Этот вопрос решается на основе специальных двусторонних федерально-региональных соглашений, фиксирующих обязательства сторон по каждому региональному проекту, условия его софинансирования и пр. [4].

Тем не менее очевидно сохраняется некая неопределенность в понимании места национальных проектов в формирующейся системе стратегического планирования. Не ясно, следует ли рассматривать эти проекты как полную или частичную альтернативу обозначенным в законе документам стратегического планирования как федерального, так и регионального уровня. Вполне возможно, что национальные проекты - временный для определенного этапа вариант целеуказания в сфрере хозяйственного и социального развития, который затем, по мере улучшения ситуации, должен быть расширен и конкретизирован, в том числе и до уровня Стратегии социально-экономического развития Российской Федерации. Наконец, национальные проекты и это на сегодня наиболее достоверная точка зрения - могут рассматриваться как новый, более актуальный и адаптированный к вызовам времени вариант структуризации государственных (целевых) программ по приоритетным направлениям хозяйственного и социального развития страны. Именно в таком - «собирательном» - контексте по отношению к государственным программам и иным подобным мероприятиям рассматриваются национальные проекты в зарубежной практике государственного управления [5].

В настоящее время в Российской Федерации действует 41 государственная программа (фредерального уровня), которая распределена по 5 проблемным блокам: «Новое качество 
жизни», «Инновационное развитие и модернизация экономики», «Обеспечение национальной безопасности», «Сбалансированное региональное развитие» и «Эффективное государство». При этом хорошо заметно, что по кругу охватываемых сфер хозяйственного, социального и политического развития страны действующая система государственных программ значительно шире проблематики нынешних 12 национальных проектов. По сути, эти проекты охватывают только первые два проблемных блока государственных программ. В экономической литературе ранее высказывалось мнение, что принятие Стратегии социально-экономического развития Российской Федерации закономерно приведет к пересмотру структуры государственных программ. В первую очередь такой пересмотр предполагался для программ территориальной направленности (блок «Сбалансированное региональное развитие») на основе Стратегии пространственного развития Российской Федерации [6]. Однако отсутствие двух названных документов стратегического планирования делает подобный вариант структурного обновления программных инструментов управления в экономике и социальной сорере невозможным.

Пока полной корреляции между национальными проектами и государственными программами не просматривается. Сейчас для выявления степени соответствия заявленным национальным проектам нужно рассматривать не только сами государственные программы в целом, но и составляющие их целевые программы. В некоторых случаях «расслоение» институциональноинструментального аппарата решения приоритетных для государства и экономики задач выглядит явно чрезмерным и не соответствующим идее консолидации бюджетных ресурсов страны. Так, новому приоритетному проекту «Малое и среднее предпринимательство и поддержка индивидуальной предпринимательской инициативы» корреспондируют (со своими собственными целевыми индикаторами и механизмами их достижения) ряд других, формально действующих документов программно-стратегического характера. Это - Стратегия развития МСП до 2030 г. [7]; так называемая «Национальная предпринимательская инициатива», включавшая 11 утвержденных Правительством РФ дорожных карт по развитию сектора МСП российской экономики (всего 837 мероприятий); целевая программа (подпрограмма 2) «Развитие малого и среднего предпринимательства» в рамках государственной программы «Экономическое развитие и инновационная экономика», в том числе интегрированные в нее приоритетные проекты по направлениям «Малый бизнес и поддержка индивидуальной предпринимательской инициативы», «Моногорода»; различные ведомственные программы, нацеленные на развитие МСП, и пр. Подобная ситуация не только «размывает» усилия и средства, направляемые на решение вполне определенной социально-экономической проблемы, но и еще более осложняет и без того непростую задачу выявления реальных итогов реализации всех этих многочисленных стратегий, программ, инициатив, дорожных карт и пр., так как не ясно, к какому именно действию следует отнести тот или иной позитивный результат или, напротив, его отсутствие, что очень характерно для положения дел в российском малом бизнесе.

В любом смысле национальное проектирование будет результативно лишь в том случае, если оно сможет не просто использовать, но и еще более усилить функцию государственных программ как наиболее эффективного инструмента организации долговременно-проектной и текущей управленческой деятельности государственных и муниципальных органов управления; как инструмента, наиболее тесно отражающего взаимосвязь ресурсного обеспечения и ожидаемых результатов и позволяющего постоянно оценивать эффективность бюджетных затрат на конкретные программные мероприятия.

Важной задачей в процессе реализации преимущественно «отраслевых» по своему характеру федеральных национальных проектов остается их согласование с теми приоритетами, которые закладываются относительно трендов пространственной структуры национальной экономики и вытекающих из этого задач государственной политики регионального развития. Однако в настоящий момент наличествуют два фрактора, которые существенно осложняют решение этой управленческой задачи.

Во-первых, непонятная задержка с принятием Стратегии пространственного развития Российской Федерации. В середине 2018 г. «официальный» проект этой стратегии появился на сайте Минэкономразвития РФ. Целый ряд обсуждений этого документа (Общественная палата РФ, Совет Федерации Федерального собрания РФ и др.) выявили достаточно критическую оценку этого документа, но тем не менее не настолько негативную, чтобы исключить возможность его позитивной доработки. Однако в начале 2019 г. этот документ вообще «исчез» и на сайте Минэкономразвития более не представлен. Эта ситуация резко усиливает дисбаланс в проработке отраслевого и пространственного «срезов» стратегического планирования в стране.

Дело в том, что стартующая система национальных проектов, наряду с уже утвержденными стратегиями и государственными программами, действительно может рассматриваться как временный субститут «базовой» стратегии социально-экономического развития страны, во всяком 
случае, в отношении некоторых основных составляющих такой стратегии. Но что касается пространственного развития российской экономики, то на фоне стартующей системы национальных проектов этот круг вопросов в смысле системного, стратегического планирования по-прежнему смотрится как практически «незакрытый». Формально на роль известного регулятора тенденций пространственного развития российской экономики может претендовать лишь добавленный к 12 национальным проектам «Комплексный план модернизации и расширения магистральной инфраструктуры на период до 2024 г.» [8]. В этот план включены 11 федеральных проектов, 9 из которых направлены на модернизацию и расширение транспортной инфраструктуры страны и ее регионов. Но при всей важности этого документа он, конечно, не может исчерпать весь круг вопросов пространственного стратегирования для российской экономики.

Во-вторых, в силу огромных различий между субъектами Федерации по основным природно-географическим и социально-экономическим характеристикам неизбежны существенные расхождения по целевым индикаторам национальных проектов в их региональном разрезе (особенно по показателям социального характера) [9]. Заметные различия касаются и тех ресурсов, которые субъекты Федерации в порядке софинансирования способны привнести для осуществления региональных проектов соответствующего профиля. Эфффективная реализация национальных проектов обусловливается не только их согласованностью с федеральными государственными программами «по горизонтали», но и согласованностью с региональными проектами и программами «по вертикали».

Кроме того, надо иметь в виду, что в отличие от фредерального центра, не располагающего на данный момент сводным документом стратегического характера (известную «Концепцию2020» едва ли можно в этом смысле сегодня воспринимать серьезно), большинство субъектов Федерации имеют либо уже утвержденные, либо доработанные стратегии своего социально-экономического развития на период до 2025 г., 2030 г. и даже 2035 г. Эти документы теперь также подлежат согласованию с теми параметрами и целевыми установками, которые будут определены для данного региона по его участию в выполнении национальных проектов.

Исходно основной замысел относительно механизма участия субъектов Федерации в реализации национальных проектов состоял в формировании в каждом из них системы особых региональных проектов [10]. Анализ той работы, которая уже проводится в этом направлении субъектами Российской Федерации, показывает, что она носит творческий характер и не сводится к простой прямой проекции федеральных проектов на региональный уровень. Это касается не только учета местных особенностей при определении целевых параметров проектов и сроков их достижения, но и самого состава региональных проектов. Например, среди федеральных проектов нет таковых, направленных на развитие институциональных предпосылок устойчивого хозяйственного и социального развития территорий.

Но среди приоритетных региональных проектов Вологодской области присутствует такое начинание, как программа «Эффрективное государство», которому нет прямого аналога среди федеральных проектов. Как отмечается в паспорте проекта, его цель - повышение эффективности государственного управления путем внедрения инновационных методов управления и кадровых технологий, упрощения взаимодействия органов исполнительной государственной власти области и граждан, снижения административных барьеров, исключения риска коррупционных факторов, снижения риска появления административных барьеров. Важно, что проект во многом затрагивает и сореру муниципального управления, которая чаще всего остается вне «зоны внимания» программно-стратегических документов федерального уровня [11].

Воронежская область принимает участие в 11 национальных проектах. С этой целью разработаны и направлены в федеральные министерства региональные составляющие по всем нацпроектам, принятым к реализации на территории области. Приоритет отдан вопросам образования, здравоохранения, развития сельского хозяйства, восстановления лесов и пр. [12]. Обозначены условия софинансирования этого участия: федеральный бюджет - 85 \%, бюджет субъекта Федерации - 15 \%. В целом в процессе участия в национальных проектах в 2019-2024 гг. планируется привлечь в экономику региона порядка 70-80 млрд р. средств федерального бюджета.

Для эффективного утверждения национальных проектов в практике государственного управления в Российской Федерации необходимо решить ряд вопросов правового и институционального характера. Главный из них - четкое позиционирование этих проектов в системе стратегического планирования согласно № 172-Ф3 [13]. Сюда следует отнести вопрос о принципах отбора национальных проектов, об определении структуры национальных проектов по «горизонтали» и по «вертикали», о логической увязке национальных проектов всех уровней с иными документами стратегического планирования, прежде всего государственными программами. Полагаем, все государственные программы целесообразно структурировать на программы в рамках национальных проектов и вне их. Первые подлежат обязательной проекции на уровне субъектов 
Федерации в виде их региональных проектов. Вторые могут оставаться чисто фредеральным инструментом государственного регулирования.

Сказанное касается также необходимости более четкого позиционирования национальных и региональных проектов и их составляющих в системе бюджетно-расходных полномочий всех органов государственного и муниципального управления, критериев определения пропорций субсидиарного софинансирования регионов и их участия в реализации проектов в зависимости от их экономического и бюджетного потенциала и пр.

\section{Ссылки:}

1. Матненко А.С. Приоритетные национальные проекты: предпосылки, сущность и проблемы правового регулирования // Вестник Омского университета. 2008. № 4 (50). С. 124-129.

2. Изгияева М.Д. Государственное управление приоритетными национальными проектами // Вестник Российского экономического университета им. Г.В. Плеханова. 2017. № 1 (17). С. 23-30.

3. О стратегическом планировании в Российской Федерации [Электронный ресурс] : федер. закон от 28 июня 2014 г. № 172-Ф3. Доступ из справ.-правовой системы «КонсультантПлюс».

4. Методические указания по порядку и типовой форме заключения соглашения между руководителем федерального проекта и руководителем регионального проекта о реализации на территории субъекта Российской Федерации регионального проекта [Электронный ресурс] : утв. протоколом заседания президиума Совета при Президенте РФ по стратегическому развитию и национальным проектам от 17 дек. 2018 г. № 15. Доступ из справ.-правовой системы «КонсультантПлюс».

5. Albrechts L. Ingredients for a More Radical Strategic Spatial Planning // Environment and Planning B: Planning and Design. 2015. Vol. 42, iss. 3. P. 510-525. https://doi.org/10.1068/b130104p ; Wolf C., Floyd S.W. Strategic Planning Research: Toward a Theory-driven Agenda // Journal of Management. 2017. Vol. 43, iss. 6. P. 1754-1788. https://doi.org/10.1177/0149206313478185.

6. Чепик О.В. Механизм программно-целевого подхода как инструмент государственного управления регионом // Потенциал современной науки. 2017. № 1 (27). С. 78-82.

7. Стратегия развития малого и среднего предпринимательства в Российской Федерации на период до 2030 г. [Электронный ресурс] : утв. Распоряжением Правительства РФ от 2 июня 2016 г. № 1083-р. Доступ из справ.-правовой системы «КонсультантПлюс».

8. Комплексный план модернизации и расширения магистральной инфраструктуры на период до 2024 г. [Электронный ресурс] : утв. Распоряжением Правительства РФ от 30 сент. 2018 г. № 2101-p. URL: http://static.government.ru/media/files/MUNhgWFddP3UfF9RJASDW9VxP8zwcB4Y.pdf (дата обращения: 03.02.2019).

9. Тамразян Д.А. Национальный проект, государство, социальный эффект // Экономика и управление: проблемы, решения. 2014. № 9. С. 16-19.

10. Валькович О.Н., Сланченко Л.И., Эдиев Р.Р. Приоритетные национальные проекты: оценка их реализации и перспектив // Экономика устойчивого развития. 2015. № 3 (23). С. 85-90.

11. Региональные приоритетные направления Вологодской области [Электронный ресурc]. URL: https://vologda-oblast.ru/prioritetnye-proekty/prioritetnye-proekty/ (дата обращения: 03.02.2019).

12. Кривошеева М.Ю. Государственные программы и проекты как формы реализации стратегических планов: опыт Российской Федерации и Воронежской области // Регион: системы, экономика, управление. 2017. № 2 (37). С. 19-25. https://doi.org/10.22394/1997-4469-2017-37-2-19-25.

13. Порфирьев Б.Н. Императивы законодательного обеспечения реализации майского 2018 г. Указа Президента России: пространственный аспект // ЭКО. 2018. № 9 (531). С. 177-191. https://doi.org/10.30680/eco0131-7652-2018-9-177-191.

\section{References:}

Albrechts, L 2015, 'Ingredients for More Radical Strategic Spatial Planning', Environment and Planning B: Planning and Design, vol. 42, iss. 3, pp. 510-525, https://doi.org/10.1068/b130104p.

Chepik, OV 2017, 'The Mechanism of the Program-Target Approach as a Tool of State Management of the Region', Potentsial sovremennoy nauki, no. 1 (27), pp. 78-82, (in Russian).

Izgiyaeva, MD 2017, 'State Management of Priority National Projects', Vestnik Rossiyskogo ekonomicheskogo universiteta im. G.V. Plekhanova, no. 1 (17), pp. 23-30, (in Russian).

Krivosheeva, MYu 2017, 'State Programs and Projects as a Form of Implementation of Strategic Plans: the Experience of the Russian Federation and the Voronezh region', Region: sistemy, ekonomika, upravleniye, no. 2 (37), pp. 19-25, https://doi.org/10.22394/1997-4469-2017-37-2-19-25, (in Russian).

Matnenko, AS 2008, 'Priority National Projects: Background, Nature and Problems of Legal Regulation', Vestnik Omskogo universiteta, no. 4 (50), pp. 124-129, (in Russian).

Porfiryev, BN 2018, 'Imperatives of Legislative Support for the Implementation of the May 2018 Presidential Decree: the Spatial Aspect', EKO, no. 9 (531), pp. 177-191, https://doi.org/10.30680/eco0131-7652-2018-9-177-191, (in Russian).

Tamrazyan, DA 2014, 'National Project, State, Social Effect', Ekonomika i upravleniye: problemy, resheniya, no. 9, pp. 1619, (in Russian).

Valkovich, ON, Slanchenko, LI \& Ediev, RR 2015, 'Priority National Projects: an Assessment of Their Implementation and Prospects', Ekonomika ustoychivogo razvitiya, no. 3 (23), pp. 85-90, (in Russian).

Wolf, C \& Floyd, SW 2017, 'Strategic Planning Research: Toward a Theory-Driven Agenda', Journal of Management, vol. 43, iss. 6, pp. 1754-1788, https://doi.org/10.1177/0149206313478185. 